\section{O conceito marxista de ideologia nos estudos de mídia britânicos}

\section{Olga Maria Ribeiro Guedes}

Professora da Universidade Federal do Ceará (UFC) Doutora pela Loughborough University - Inglaterra

\section{Introdução}

O conceito de ideologia tem sido descrito na literatura como um conceito vago, escorregadio e, para alguns, 'inútil' (Frazer, 1988). Como bem coloca McLellan 'ideologia éo mais elusivo conceito dentro das ciências sociais... essencialmente um conceito contestado, isto é, um conceito sobre o qual existe controvérsia em termos de sua própria definição e aplicação.' (McLellan, 1986: 1)

N estetrabal ho não há espaço para uma exaustiva revisão do conceito de ideologia desde De Tracy até hoje, mas somente para discutir como o concei to tem sido apropriado pelos estudos da mídia, que se expressa no debateentreos chamados Estudos Culturais ea Economia Política. O primeiro refere-sea perspectiva que privilegia os aspectos culturaisinspirando-senaleituradeGramsci, e o segundo na abordagem que coloca mais ênfase nos determinantes políticos e econômicos dos produtos culturais da mídia.

A pesar dassignificantes diferençasentre estas duas perspectivas teóricas, alguns autores sugerem queexisteum certo exagero nesta diferenciação, como por exemplo Curran ao colocar que 'ambas trabal ham dentro de um modelo neo-marxista de sociedade, ambas percebem uma conexão, entreosinteresseseconômi coserepresentação ideológica e ambas retratam os meios de comunicação como servindo mais aos interesses dominantes do que aos interesses socialmente universais' (Curran, 1990: 139). Serão considerados nesta discussão as abordagens do CulturalismoM arxistaapartir deRaymond Williams, dos estudos deStuart Hall no 'Centre for Contemporary Cultural Studies' em Birmingham-Inglaterra e a 
tradição da Economia Política, que a nosso ver constituemo centro da 'Tradição Crítica'. Devido a limitação de espaço, não discutiremos as teorias da Sociedade de Massa, da Escola de Frankfurt e da Liberal-Pluralista, que, deformasdistintas, influenciarama'Tradição Crítica'.

Antes deanal isarmoso uso do conceito de ideologia no estudo da mídia destas abordagens, faz-se necessário relembrarmos, resumidamente, o conceito de ideologia em Marx, o qual tem servido de pano de fundo para a 'Teoria Crítica'.

\section{Ideologia em Marx}

O conceito de ideologia é um dos menos elaborados nos escritos de Marx (Larrain, 1979; Bennett, 1982, McLellan, 1986). Ao invés de uma análise estruturada e definida do conceito, o que temos é um esboço de suas preocupações com o tema.

A maisaprofundadaanál isesobreideologia é encontrada no texto A Ideologia Alemã, escrito junto com Engels, que é uma crítica a noção francesa de ideologia e um ataqueaosJ ovens Hegelianos. Deacordo com eles, osJ ovens começaram a discutir o conceito deideologiaa partir daconsciênciaeidéias enão da realidadematerial. Estaéa basepara a crítica de Marx sobre o Ideal ismo A lemão. 'A consciência deveser explicada a partir das contradições da vida material e as pessoas não conseguem solucionar suas contradições a partir da consciência, senão são capazes de resolvêlas na prática'. (M arx eEngels, 1970: 41). Na I deologia A lemã, Marx e Engels apresentam uma teoria materialista deideologia, queenfatiza duas idéias: primeiro, queideologia éuma representação do mundo a partir do ponto de vista da classe dominante, que detém os meios de produção e segundo, a idéia de que esta representação do mundo é necessariamente distorcida porque representa os interesses da classe dominanteenão os interesses da humanidade como um todo, isto é, a ideologia tem um papel importante na manutenção das relações de dominação.
No velho Marx ideologia não é uma invenção, ilusão ou uma negação da realidade, mas refleteo real por si mesma. A ideologia évista como uma projeção na consciência das pessoas, de idéias produzidas por suas práticas. Assim, a ideologia se apropria da aparência do real, dando as pessoas a impressão deautonomiaeindependência. A natureza da ideologia de mercado, por exemplo, não é falsa no sentido de que não existe, mas é falsa por não expressar completamente as relações sociais sobre as quais o capitalismo se baseia.

Este foi um breve e parcial esboço do conceito de ideologia em Marx. Outras questões referentes a este conceito serão abordadas quando considerarmos os escritos dos Marxistascontemporâneossobrecultura, ideologia e mídia.

\section{3 'Culturalismo' marxista}

A noção de 'Culturalismo' marxista é usada para chamar a atenção para o trabal ho de escritores tais como Raymond Williams, Edward Thompson, Christopher Hill e, menos freqüentemente, Richard Hoggart e Eric Hobsbawn. O trabal ho deRaymond Williams traz substancial contribuição para os estudos de literatura crítica, cultura, teoria política, ideologia e mídia.

Juntamente com outros escritores da 'N ovaEsquerda' inglesa, Raymond Williams era consciente de que o economicismo evidente no pensamento Marxista era insuficientepara dar conta da crescente importância das culturas democráticas e comerciais. Em seus últimos escritos, Williams oferece uma análise material do processo cultural. A teoria do materialismo cultural tinha a intenção de criticar as noções marxista de base/ superestrutura e reificaçao de formas abstratas queelelocalizou emcertastendências do pósestruturalismo.

A metáfora da base/ superestrutura emergiu como um problema central na teoria Marxista. Estanoçãoétomadaparasignificar que a base (econômico) tem prioridade 
explicativa ou estabelecelimitessobreasupe restrutura (instituições culturais e políticas). Recente análises marxistas sobre o assunto, namaioriainspiradapor Gramsci eA Ithusser argumentam quea superestruturatem, pelos menos, uma relativa autonomia em relação a base econômica (Geras, 1987). Ao contrário destes autores e, apesar de ser associado ao Marxismo, Williams mostrou-se cético em relação a metáfora da base/ superestrutura por algumas razões, sendo que a mais importante é que, para ele, tal argumento reduz a superestrutura a um reflexo da base.

Williams considera que denominar um fenômeno como superestrutural, é situá-lo emumnível 'menor' derealidade. A superestrutura, nesta leitura, torna-se uma esfera dependente de idéias que refletem a base econômica material. O 'rebaixamento' da superestruturaaumaesferaidealista, vai contra a vontade de Williams de demonstrar que as práticas culturais são também materiais. Sua teoria do culturalismo material considera que todas as práticas sociais são constituídas de significado e elementos materiais.

Williamsdemonstraseu argumentocom uma discussão do texto de Marx no Grundrisse. Marx, de acordo com Williams, argumenta que o trabalhador que constroí um piano está envolvido em uma atividade produtiva, ao passo queum pianista tocando piano não está. Isto acontece porqueo trabaIhador está diretamente envolvido com a reprodução social dotrabal ho, eo mesmonao poderiaser dito sobreo pianista. A o contrário de Marx, Williams insiste que a prática de tocar o piano é, simultaneamente material e simbólica (Williams, 1982).

N os anos 1960 e 1970, Williams voltouseparaaleiturado trabal ho sobrehegemonia de Gramsci, como tantos outros autores da esquerdabritanicaqueprocuravam pelo'nãoreducionismo' marxista (Forgacs, 1989; Ransome,1992). Em resumo, um grupo dominante pode ser considerado hegemônico se transcedeo limite do interesse econômico e provém o povo com liderança moral eintelectual. Hegemonia é melhor percebida enquanto um campo de batal ha contínuo, onde aburguesiaeaclassetrabal hadoraconstroem al iançaseconômicas, políticaseculturaiscom outros grupos sociais. Para Gramsci, ideologia é representada como o 'cimento social' que gera alianças entre classes sociais diferentes. Deacordo com Gramsci, nóspodemos julgar se uma ideologia é eficiente se esta é capaz de se 'conectar' ao senso comum das pessoas e mobilizá-las para mudanças (Gramci, 1971).

Em seu livro $M$ arxismo e Literatura, Williams definehegemoniacomo um processo histórico contínuo que está sempre mudando e não é estático ou sistemático em sua formação. A prática hegemônica pode ser tanto dominante, residual ou emergente, embora, como explica Williams, nenhuma ordem social pode incorporar toda a experiência humana. Consequentemente, certas práticas sociais, como por exemplo, ensinar Marxismo dentro da universidade ou trabal har para uma organização para AIDS, são contraditoriamente de oposição, no momento em que estas práticas, simultaneamente, desafiam e reafirmam a hegemonia dominante (Williams, 1979).

O hegemônico é a combinação de processos culturais como as tradições e instituições. A produção e reprodução material de tradições inventadas são largamente dependentes de instituições como os meios de comunicação eo sistema escolar. A transmissão cultural dessas tradições através das instituições, ajudam a formar um consenso dominantenasociedadecontemporânea. Portanto, segundo Williams, não se pode examinar os processos decomunicação na sociedademoderna, sem examinar essas instituições (Williams, 1961).

Quando da análise da indústria cultural, uma questão importante é a função econômica que ela desempenha para o capital. Historicamente, os meios de comunicação estãoligadosa habilidadeda baseeconômica emcriar lucrosatravés deformasmaisdiretas de produção. $O$ formato da superestrutura tem seconstruído através do econômico, porquesão as relações sociais que determinama distribuição do lucro. Investimentos na in- 
dústria cultural podem ser entendidos como sendo produto do aumento dos lucrose uma procura por novas áreas de investimentos. N esta leitura, a superestrutura não tem um desenvolvimento autônomo, masé concretamente ligada ao nível econômico. Assim, a análise de Williams é correta ao estressar a materialidade das práticas sociais, mas, para alguns autores, falha, em reconhecer o determinismo da esfera econômica. Se a teoria dos meios de comunicação tivesse que se reorientar pelo domínio da economia, esta não poderia analisar as diferentes nuanças culturais do fenômeno damídianaseconomias capital istas. A o contrário de autores como Garnham e Dallas Smythe que persistentemente minimizam o papel ideológico das formas simbólicas materialmente produzidas, Williams procura fazer esta conexão entreos níveis da economia política eo produto cultural, porque é necessário estudar a complexa interação entre as esferas cultural, econômica e política.

Uma outra crítica sofrida por Williams se refere ao conceito de classe. Classe é uma categoriacentral natradição Culturalista, mas édiscutida deforma específica. Classeépensada como um conjunto de relações entre pessoas. Como tal, relações de classe sao entendidas em termos interpessoais. $\mathrm{O}$ quea noção de classe faz nos Estudos Culturais é essencialmente deslocar a idéia das relações de produção para as 'relações' enfatizando o humanístico e psicologico destas 'relações'. Assim, os culturalistas analisam as relações econômicas em termos de 'sentimentos' enão só como um processo sócio-econômico e entendem o conceito de classe não com uma compreensão 'externa' aclasse, masenfatizam o 'sentimento de classe'. De acordo com Johnson, existe pouca atenção sobre o que/ como estas relações são construídas (meios de produção evalor do lucro). A ssim classeé construída 'de forma que sistematicamente marginaliza um aspecto (econômico) desta categoria, isto é, a conexão entre classes e as relaçoes deprodução em particular os modos de produção'. (Johson, 1979: 65)
Os estudos culturais britânicos são melhor representados pelos estudos desenvolvidos pelo Centre for Contemporary Cultural Studies da Universidade de Birmingham e seu diretor Stuart Hall, que se preocuparam em estudar temas ligadosa cultura, ideologia e identidade a partir de uma sofisticada reinterpretaçao de alguns pensadores centrais do pós-estruralismo e de uma leitura própria de Gramsci.

Gramsci é analisado a partir de sua resistência a tendência de alinhar questões culturais e ideológicas com as questões econômicas edeclasse. Seu trabalho étido como uma recusa a qualquer forma de reducionismo. As sociedadessão vistas como complexasformaçõessociais, como bloco históricos, necessitando analises concretas e específicas de forma a elucidar a relação em 'estrutura e superestrutura'.

O conceito central é o de hegemonia. Para Hall, hegemonia significa mais do que simplesmente poder cultural e ideológico, refere-seatodosos'processosondeumgrupo social quealcançou a liderança econômica, é capaz de expandir isto para uma liderança social, política ecultural através da sociedade civil e do estado' (Hall, 1980: 35).

O que Gramsci oferece, Hall argumenta, é uma forma não-reducionista de pensar sobre a clássica questão de determinismo econômico, a relação entre base e a superestrutura. Contra a formulação da Ideologia A lemã (as idéias dominantes...). Hall coloca quea posição de classe e os fatores materiais são necessários, mas não suficientes como ponto de partida para a análise de qualquer formação ideológica.

$\mathrm{H}$ all tentou repensar as conexões entre diferentes níveis da formação social com o conceito dearticulação, quefoi desenvolvido por Laclau e Mouffe (1976). O argumento é quenão existeumanecessária, determinadae absoluta conexão entre diferentes práticas sociais, mas que existe um caminho para perguntar como elementos ideológicos pas- 
sam a se conectar sob certas condições históricas. Portanto, a teoria da articulação é um ataque a idéia de que existe uma necessária relação entre os meios de produção eideologia. Nega não a idéia de correspondência, mas de necessária correspondência. Mais do que ver a correspondência como dada, Hall pensa sobreelas como historicamenteproduzidas e como resultado da política.

Com relação aideologia, Hall a compreende como um fenômeno discursivo, conceituado em termos da articulação de diferentes elementos. IdeologiaparaGramsci éteorizada como tendo dois domínios: filosófico (ideologias teóricas) e senso comum. O papel das 'ideologias orgânicas' é interferir no terreno do senso comum. O senso comum éa estrutura da ideologia popular, uma 'concepção espontânea do mundo', que engloba traços dos sistemas de pensamento prévio os quais sesedimentam no cotidiano. Como Gramsci, Hall estainteressado narelação entrefilosofia (teoriaideológica) esenso comum no processo de sedimentação ideológica, como por exemplo ao tentar compreender o 'Thatcherismo' como um 'processo hegemônico'. Não significa que o 'Thatcherismo' alçancou hegemonia ou foi um fenômeno puramenteideológico, porque a compreensão de Hall de hegemonia dar ênfase à importância do 'núcleo decisivo' da atividade econômica, mas que representou uma particular articulação de elementos. Ideologia foi vista como forjando uma nova articulação discursiva entreo discurso liberal do 'mercado livre' e do 'homem econômico' com os temas conservadores de família, nação, patriarcado e ordem. O que Hall mostra é que estes elementos ideológicos não foram colocados juntos de forma completamente trabalhada, mas que o 'Thatcherismo' era a tentativa do 'refazer' do senso comum: seu objetivo era setornar o senso comum deuma era (Hall, 1988: 8).

A pesar do compromisso deHall em ver ideologia como um fenômeno discursivo, o quenão aparece em seus trabal hos (especialmente no texto sobre Thatcherismo) é uma análise detalhada do significado da lingua- gem dentro detodo o processo de mudanças política e ignora o contexto de recepção da ideologia do Thatcherismo. Frequentemente Hall é criticado por considerar que os fenômenos que eleanalisa são puramente ideológicos. Estudiosos da tradição da economia política se perguntam se Hall deu suficiente atenção ao nível econômico. Paraelesaênfase na relativa autonomia do econômico levou a autonomia da ideol ogia eas análises não tem levado em conta o equilíbrio do poder de classe ou a relação entre o econômico e o ideológico. O trabalho deH all tendea colocar a questão do determinismo econômico em um parêntese teórico, o qual só é lembrado para sinalar sua posição Marxista. O que se precisa é uma integração das análises dos níveis econômico e ideológico (Murdock, 1995).

Dentro da área de comunicação, uma das contribuições específicas de Hall é de ligar as formas culturais ideologicamente codificadasasestratégias dedecodificaçao da audiência. Ao fazer esta ligação, simultaneamente considera as mudanças do contexto político dossignosdamídiaedasmensagens. ParaH all, ostextosideologicamentecodificados continuam sendo o primeiro nível de determinismo. Com relação aos meios decomunicação, Hall argumenta que estes formam a principal instituição ideológica do capitalismo contemporâneo, i.é, os sistemas de comunicação formam o principal espaço no qual o consenso dominante é forjado.

Assim, para Hall, os sistemas de comunicação são o principal domínio simbólico através do qual a 'fabricação' de consenso é forjada. Os meios de comunicação operam através daprodução decódigoshegemônicos que 'cimentam' o social. Os códigos que representam o real são coletados desdeo limitado campo dos discursos dominantes atéuma restritasériedeexplicaçõessociais. Oscódigos preferenciais alcançam seu efeito ideológico aparecendo como naturais. Seguindo Althusser, como a linguagem não refletiria o real, poderia-sefalar do efeito derealidadeda ideologia. A experiência da realidade não mediada é simbolicamente construída atra- 
vés da linguagem. Assim como o sujeito se engana a respeito da fonte desua identidade, a mídia parece refletir a realidade enquanto na verdade está construindo esta realidade.

Ao contrário da atenção que Hall deu a mensagem mediada, ele tem pouco a dizer sobreas instituições dos meios de comunicação. Na sua análise sobre o fenômeno Mrs. Thacher ele oferece uma limitada discussão sobre o impacto do estado e do capital nos meios decomunicação. Maissignificativo do que esta relação é a limitada estrutura de interpretações dentro da qual os jornalistas operam. Entretanto, Hall corrigiu estaanálise interna por uma ênfase estrutural nas fontes jornalísticas. O que é aparente é que a interseção do contexto cultural do jornal ismo eo conteúdo semiótico das mensagens da mídia continuam determinante para Hall.

Os trabal hos do grupo de Birmingham trazem uma contribuição efetiva para a análise da mídia, mas sofrem críticas por concentrarem-semais nos meios ideológicos do que em outros níveis de determinação, tais como posse e controle dos meios de comunicação quesão deixadosfora dasanálises. A pesar de sua complexa teoria da produção ideológica, ele falha em localizar a produção cultural ao nível da análise institucional. A parte esta crítica, Hall é mais considerado por sua análise einterpretação das mensagens da mídia, o queeventual menteo levou aquestões sobre a audiência, iniciando uma importante contribuição ao estudo darecepção, quefoi negligenciado por Williams, pelo grupo de Glasgow epelaEconomiaPolítica (Hall, 1975; Hall et all, 1978).

Ao reconceituar o determinante papel dos meios de comunicação, Hall utilizou os escritosdeSaussuresobreanaturezaarbitrária dossignoslingüísticos edeBarthes aidéia de significante e significado, que Hall amplia para afirmar que discursos possuem significados dominantes que estruturam o significado da mensagem. Ao concentrar-se na ideologia do texto, Hall estaria privilegiando a mensagem na construção da subjetividade. Mais tarde ele voltou atrás nesta posição e permitiu as 'leituras de resistência' aos textos da mídia e deu ênfase a natureza polisêmica do significado. O queéoferecido por Hall éuma crítica radical a idéia dequeas estruturas depropriedadedeterminamoconteúdo da mídia. Na produção da mensagens dos meios, Hall estabeleceuma distinção básica entre 'encoders' e'decoders'. Eleidentifica uma quebra radical entre a estrutura de conhecimento, relações de produção e infraestrutura técnica que facilitam o processo de codificar e decodificar as estruturas de significado. Codificar um texto da mídia depende de normas e procedimentos profissionais, relações institucionais e equipamentos técnicos. Uma vez que a mensagem tenha sido simbolicamente codificadaestáaberta as estratégias deleitura empregadas pela audiência. A recepção da audiência é dependente de sua disposição cultural e política, de sua relação com as estruturas mais amplas de poder eseu acesso atecnol ogiademassa(radio, tel evisão, vídeo, disco compacto, etc.). Existem três maneiras pelas quais um texto simbolicamente codificado pode ser lido: leitura hegemônica dominante, que interpreta o texto em termos do significado preferido sugerido pela mensagem; leitura negociada, onde o significado produzido pela interface entre o intérprete e o codificador da mensagem é sutilmentecontestado. A ceitando a estrutura geral sugeridapel ocódigodominanteapessoa dáumsignificado contraditório a mensagem; a leitura deoposição iria ter uma compreensão contra o argumento do texto e faria poucas concessões paraaperspectivaoferecida. Estas três formas de interpretação são oferecidas como meio de localizar o texto dentro das estratégias discursiva dominante, enquanto ligando-as a uma já 'codificada' audiência (Hall , 1980).

A pesar dainegável contribuição deHall aos estudos da mídia, seu trabalho continua limitado devido a sua preocupação com o discurso. Ele exagera o poder das estratégias ideológicas enão ofereceuma análisepolítico econômica dos meios de comunicação. Embora correto ao enfatizar a importância da relação entre a questão da construção 
discursiva da mensagem e a compreensão interpretativa da audiência, o nível determinante estaria em outro lugar. $O$ que esta faltando éa análise de como a economia eo estado moldam a produção cultural. Seus últimos escritos tendem a negligenciar como as 'reais' relações sociais dão formaa construção das mensagens da mídia, bem como ao contexto de recepção (Golding e Murdock, 1979).

\section{Economia Política}

A abordagem da Economia Política éo nome dado aos trabal hosqueanalisama mídiacom um interesse nos determinantes econômicos que interferem na produção dos produtos culturais e da comunicação. Não é possível falar de uma abordagem político-econômica pois existem diferenças entre as pessoas trabal hando nesta tradição. Referimo-nos ao trabal hodeJamesCurran, Nicholas Garnham, Peter Golding e Graham Murdock, isto não quer dizer queotrabal ho destespesquisadores éhomogêneo, massimplesmentemostrar uma continuidade de interesse (por ex. Golding e Murdock, 1979; Murdock e Golding, 1977; Garnham, 1977, 1979, 1988; Curran, 1987,1990, 1994).

A EconomiaPolíticapodeser entendida como uma reação contra a tendência culturalista dos anos 70, particularmente a associada com Hall e outros do Centro de Birgminham, que teria respondido a questão do reducionismo simplesmente ignorando completamente o nível econômico e enfatizado a relativa autonomia da ideologia as custas de analisar as formas pelas quais os fatores econômicos formatam a produção cultural.

Os teóricos da Economia Política enfatizam a importância da organização econômica e tem sido cautelosos com a questão do determinismo econômico, como coloca Golding e Murdock ' nos não estamos dizendo queas forças econômicas são o único fator a estruturar a produção cultural, ou que ele seja sempre o mais significante...nos não ne- gamos a importância do controle imposto pelo estado e pela esfera política ou o significado da inércia exercida pelos códigos culturais dominantes e tradições. Nem estamos negando a autonomia relativa da produção pessoal e os pertinentes efeitos das práticase ideologiasprofissionais'(GoldingeM urdock, 1979: 198).

O ponto de partida para análise tem sido o exame da tendência em torno da concentração de propriedade e conglomerados na comunicação e em outros setores. O que eles argumentam éque não é simplesmente quepoucascompanhiaspredominamemcada setor, mas que as grandes firmas tem importante posição de comando simultaneamente em diferentes setores (videcaso rede Globo). Deacordo com eleséparte de uma tendência geral em torno da diversificaçao, isto é, o processo pelo qual uma companhia com interesses em um setor adquire novos interesses em outros setores.

Murdock identificatrêstipos básicos de conglomerados queoperam naárea da cultura e comunicação - conglomerados industriais, de serviços e comunicação. Dois processos tem sido importantes na re-estruturação do campo de atuação dos conglomerados: inovação tecnológica e privatização. A EconomiaPolítica, ao considerar asinovações tecnológicas, recusa o determinismo tecnológico e se preocupa com as relações sociais e econômicas através das quais as tecnologiastem sedesenvolvido edentro das quais tem se inserido. Crucial nisto, éo processo de privatização, que pode melhor ser entendido como abrangendo vários componentes, incluindo a desnacionalização (do público para o privado), a introdução de políticas 'liberalizantes' desenhadas para introduzir a competição entre mercados, e a regulamentação da indústria da comunicação, mudando sua 'filosofia' da defesa dos interesses público em torno da promoção dos interesses da companhia.

Esta tendência significa que uma das principais perguntas feita pelos teóricos da Economia Política, qual seja: até onde um sistema de comunicação dominado por em- 
presas privadas garantea diversidade de informação e discussão necessária para uma efetiva cidadania, é mais do que nunca altamenterelevante. Estamosnos dirigindo para uma era onde 'a combinação das mudanças tecnológicas e as políticas de privatização estão gerando enormes conglomerados com uma inigualável capacidade de estruturar o meio-ambiente simbólico no qual todos nós vivemos' (Murdock, 1990: 2). O que está em questão éprecisamentea natureza eforma de determinismo exercida por este tipo de propriedade.

Não negando a importância destes 'insights', o que parece estar faltando é a tentativa de ir além das análises do impacto geral dos padrões de propriedadee analisar a direta intervenção dos donos sobre o conteúdo da mídia. Também não existe uma análise dos modos como o processo de influencia da organização econômica sobrea variedade e natureza dos produtos disponíveis na mídia funciona em situações concretas - e não somente naquelas situações nas quais a mão do proprietário podeser vista claramente. Estaquestãolevaaoutrasindagaçõessobre a mediação dos determinantes econômicos.

Nos idos dos anos 80 al guns estudiosos daEconomiaPolítica passarama centrar suas análises sobre as novas tecnologias da informação e comunicação. Estes trabalhos centraram atenção em duas questões: como estão sendousadasastecnologias decomunicação para aliviar a crise econômica, e que impacto estas tecnologias de comunicação teriamemdiminuir as desigualdadessociais? Golding eMurdock apontam queexistedesigualdade de acesso aos produtos culturais. Estetipo de pesquisa nos diz que os padrões de propriedade das novas tecnologias reproduzem as desigual dades já existentes. $O$ que é difícil de aceitar é a implicação de que o nível de renda seja o único determinante de que uma pessoas irá consumir um produto cultural ou não.

Nos últimos anos, Nicholas Garnham vem tentando ampliar o escopo teórico e empírico da Economia Política. Em 1979 ele responde ao desafio colocado por Raymond
Williamquechama por uma revisão nateoria cultural deformaa dar conta daexpansão das forças capitalistas na produção cultural e da mídia. Mesmo fiel a tradição da Economia Política, Garnham declara que a (re) produção cultural está sujeita a determinantes econômicos, mas acrescenta que uma distinção deveserfeitaentreo 'material' eo 'econômico'. O primeiro seria uma categoria geral que se refere as características essenciais das relações sociais de produção deformas culturais. O 'econômico' se refere as formas especificas do capitalismo, isto é, das relações sociais de produção edistribuição decapitalismo. Desde que esta forma capitalista é incompleta e engloba um processo contraditório, é necessário entender como e em que extensão a esfera cultural tem sido absorvida pelo processo de produção de bens (Garnham, 1979).

\section{Conclusão}

Historicamente o Marxismo tem oferecido uma análise dos meios de comunicação de massaquetem procurado enfatizar seu papel na reprodução social do status quo. Onde o Liberalismo sugere que os meios de comunicação desempenham um papel na manutenção de um livre discurso, o Marxismo assegura queas relações sociais desiguais temajudado aformar imagensideológicas da representação da sociedade. Nestesentido, o Marxismo sugere que existe uma ligação entre questões de propriedade e o conteúdo cultural do produto da mídia. O Marxismo tem criticado o Liberal ismo por assumir que a livre troca de idéias pode acontecer em condições dedominação declasse. Entretanto, as limitações M arxistas são também consideráveis: tem negligenciado outros modos de dominação não relacionadas a classe, como gênero e raça e não tem dado efetiva atenção ao papel do estado. É notório quenos países Europeus administrados pelo estado, sociedades socialistas, o fluxo de informação e a sociedade civil eram altamente controladas. Isto e a presente crise de identidade do Marxismo coloca difíceis questões a cerca de seu 
papel enquanto uma teoria crítica. A pesar de suas limitações, as teorias cultural istas epolítico-econômica tem contribuído para nossa compreensão da cultura dos meios .

\section{Bibliografia}

ALTHUSSER, L. Essays on Ideology. Londres, Verso, 1984.

BENNETT,T. Theories of the media, theories of sociey'. In: Gurevitch, M, Curran, J. e Wollacott, J. (eds.) Culture, Socity and the M edia. Londres, Methuen, 1982.

CURRAN, J. The new Revisionism in mass communications research: a reappraisal. European Jornal of Communication, 5: 135-164, 1990.

CURRAN, J., GUREVITCH, M. eWOOLLACOTT,J. The study of the media: theoreica approaches'. In: Body-Barreto, 0, Braham, P. (eds.) M edia, Knowledge and Power. Milton Keynes, Open University Press, 1987.

CURRAN, J. e SEATON, J. Power Without Responsability; the press and broadcasting in Britain. Londres, Fontana, 1994.

FORGACS, D. Gramsci and M arxism in Britain. New Left Review, 176:70-88, 1989.

FRAZER, E. Talking about Feminity: the concept of ideology on trial. Tese de doutorado não publicada, Universidade de Oxford, 1988.

GARNHAM, N. 'Towards a political economy of culture'. New Universities Quartely, 31(3): 341-57, 1977.

. 'Contribution to a political economy of mass communication'

$\bar{M}$ edia, Culture and Society, 1:123-46. 1979

. 'Raymond Williams, 1921-1988; a Cultural analyst, a distinctive tradition'. Journal of Communication, 38 (4). 1988.

GERAS, N. 'Post-Marism?'. Nen Let Review, 163 (May-June): 40-82, 1987.

GOLDING, P. e MURDOCK, G. IIdeology and the mass media: the question of determination'. In: M, Barret etall. Ideology and Cultural Production. Londres,Croon Helm, 1979.

GRAMSCl, A. Selections from Prision N otebook. Londres, Routledge, 1971
HALL, S. Television as a Medium and its Reations to Culture, CCCS Occasional Paper, Birmingham, 1975.

HALL, S. 'Encoding and decoding'. In: Culture, Media and Language. Londres, Hutchinson, 1980

HALL, S. Thatcherism amongst the theoriss: toad in the garden'. In: C, Nelson and L, Grossberg. Marxism and Interpreation of Culture. Londres, Macmillan, 1988.

HALL, S. et all. (eds) Poliaing the Crisis: M ugging, the State and the Law and Order. Londres, Macmillan, 1978.

JOHNSON, R. 'Histories of culture/ theories of ideology: notes on an impasse'. In: M, Barret op.at.

LACLAU, E. e MOUFFE, C. Politics and Ideology in Marxist Theory. Londres, Verso, 1976.

LARRAIN, J. The concept of Ideology. Londres, Hutchinson, 1979.

MARX, K. e ENGELS, F. The German Idelogy. Londres, Lawrence \& Wishart, 1970.

McLELLAN, D. Idelogy. Milton Keynes, Open University, 1986.

MURDOCK, G. 'Redrawing themap of thecommunicationsindustries: concentration and ownership in the era of privatisation'. In Ferguson, M. (ed.) Public Communications: The new imperatives. Londres, Sage, 1990.

MURDOCK, G. 'Across the great divide cultural analysis and the condition of demoracy'. Critical Studies in Mass Communication, 12: 89.95, 1995.

MURDOCK, G. e GOLDING, P. 'Capitalism, communication and dass relations'. In: M ass Communication and Society. Milton Keynes, Open University Press, 1977.

RANSOME, P. Antonio Gramsci: a new introduction. Hemel Hempstead, Harvester Wheatsheaf, 1992.

WILLIAMS, R. Culture and Society (1780-1950). Harmondsworth, Penguin, 1961

WILLIAMS, R. Marxism and Literature. Oxford, Oxford University Press, 1979.

WILLIAMS, R. Culture Londres, Fontana, 1982. 